\title{
Unfinished MDG agenda highlighted at the first Global Maternal Newborn Health Conference
}

\author{
Yuba Raj Paudel ${ }^{*}$ \\ Nepal Health Sector Support Program, Ministry of Health and Population
}

Received:

29 November 2015

Revised:

12 December 2015

Accepted:

23 December 2015

\section{${ }^{*}$ Correspondence: yubaraj.paudel@gmail. com \\ Nepal Health Sector Support Program, Ministry of Health and Population, Kathmandu, Nepal. GPO Box: 7830}

Dear Editor,

Less than a month after launching of sustainable development goals (SDG) by UN general assembly (1), and the Global strategy for Women's, Children's and Adolescents' health, a landmark conference was hosted in Mexico City from October 18-21 2015 (2). The conference was hosted by Mexico's secretariat of health and convened by USAID's flagship Maternal and Child Survival Program, Maternal Health Task Force at Harvard School of Public Health and Save the Children's Saving Newborn Lives. The conference provided a unique opportunity to reflect on unfinished agenda of millennium development goals (MDG) and prioritize tasks for the post-MDG period. As Temmerman and colleagues have underlined the need to identify transformative actions to create an environment where women and children can survive and thrive (3), the conference saw more than 1000 delegates and public health experts from 75 countries sharing information, spurring ideas for solutions, designing strategies and networking to meet targets outlined in SDGs and the global strategy.

The conference was organized around the themes of quality of care, equity and integration of services (4). The plenary sessions, skill demonstrations and discussions were grouped into 6 major tracks: "innovating to accelerate impact at scale, measuring for evaluation and accountability, bridging equity divides, generating new evidence to fill critical knowledge gaps, strengthening demand for health care and increasing health systems' capacity to respond to population needs (4).”

This paper brings in my experience as a participant of Global Maternal Newborn Health Conference, 2015 which dealt with unfinished MDG agenda on maternal and newborn health and way forward, with particular reference to low- and middle-income countries.

\section{The unfinished agenda}

Between 1990 and 2015, the global maternal mortality ratio has been reduced by 47\% (5). Under-five mortality has dropped 53 percent in the same period (6). However, still more than half of women do not receive recommended amount of antenatal care. World-wide, 800 women still die each day during pregnancy and childbirth. Furthermore, 7300 still births, 16,000 under-five deaths-including 7400 newborn deaths occur world-wide everyday (2).

While increasing access to care received attention during MDG era, quality of care was often overlooked. Most of the countdown countries have a severe shortage of trained health workers with a median of 10.2 physicians, nurses and midwives per 1000 population against a WHO benchmark of 22.8 per 1000 (7). The looming inequality within and among countries was counted as a major setback for the maternal and child health. Within countries, development so far has bypassed women and those from lower economic ladder. People from selected ethnicities, those with disability and from rural and remote regions remain disadvantaged. The 2015 countdown report shows that inequity is higher for institutional based care or those requiring repeated contacts with health workers (skilled attendance at delivery, antenatal care and care seeking for pneumonia) compared to community based care such as immunization, and exclusive breastfeeding (7). Harvard FXB Center's Policy Director Alicia Yamin stated, “These egregious inequities in maternal and child health are not tragedies, they are injustices."

\section{What needs to be done?}

About half of the 68 countdown countries have been graduated from countdown by reducing maternal or child mortality below the threshold level (7). However, increasing equitable coverage of quality health care remains a continuing challenge to many countries including Nepal. These challenges need to be addressed by implementation of supportive health policies, increased investment, and stronger health systems. Ana 
Langer, one of the co-chairs of the conference said, "Many of these deaths can be prevented by using evidence and technologies we have today. By making them available to all who need." As a matter of priority, we need to count still births, break the taboos regarding still-births and increase investment for prevention of still births and child disability along with action on maternal and neonatal health in the coming days.

Quality of care that encompasses provision of the evidence based care and respectful care in an enabling environment for health care providers need to be at the centre of maternal and child health services. Innovations in service delivery can be employed to accelerate progress on maternal and child health. Mobile health technologies and other innovations can be leveraged to increase demand for and access to reproductive health services as employed in India, Nigeria and Bangladesh.

Change can be accelerated by working together. With strong leadership, by implementing context specific interventions, with the support from good people and accountable system, progress can be accelerated. In the opening ceremony of the conference, Co-chair and trustee of Bill and Melinda Gates foundation, Melinda Gates opined, "Extraordinary progress is possible. By working together and integrating our efforts, we can collectively achieve greater impact, enabling more women and children to survive and thrive (2). She further added "Investing in the health and well-being of women and children is one of the smartest things countries can do. It enables them to take advantage of economic opportunities and achieve long-lasting benefits for their families, communities and nations." Experiences from Mexico, Nepal and Ethiopia among others have demonstrated what can be achieved when governments, UN agencies, donors and NGOs work together. This requires increased spending on reproductive, maternal, and child health as has occurred in Peru and Ethiopia by garnering political support, thus making care affordable to lower income and disadvantaged groups (7).

Wherever possible, integrated services need to be delivered through a gradually strengthened primary health care system. Professor Joy lawn, from the London School of Hygiene and Tropical Medicine, UK noted that integrated care for mothers and children particularly around the time of birth is likely to garner a triple return on investment in the prevention of maternal and newborn deaths as well as still births and disability. Zulfiqar A Bhutta, an eminent public health expert and the moderator of the panel for Integrated care, made it clear during his concluding remarks that a mix of strategies contextualized to local needs is required for delivering integrated care. He further stressed, "A political commitment and change in technology and skill mix at administrative level is required. The aim of integration of services should not be to save money for the health system. The whole theme of the service integration should be to provide quality service and eliminate persisting inequalities in health service utilization and health outcomes." The need to integrate financial aid from donors rather than funding for specific projects was also emphasized by conference participants as an important component of integration of care.

Hence, the conference proved to be instrumental by providing a platform for the global maternal and child health community to better understand and respond to the most urgent needs for mothers and children and to remember that, in the Lancet's editor, Richard Horton's words, "It's the time to take action and fight back". All in all, the conference provided a unique opportunity to reflect on MDG's unfinished agenda and pave a path for SDGs and the Global strategy for Women's, Children's and Adolescents' health.

\section{Acknowledgements}

The author would like to thank Dr. Neena Khadka Basnet, Maternal and Child Survival Program and Shelly Parker, Top End Health Services, Australia for their critical input on the first draft.

\section{References}

1. United Nations. Sustainable Development Goals 2014; Available from: http://www.un.org/sustainabledevelopment/sustainable-development-goals/.

2. GMNHC. Global Maternal Newborn Health Conference Begins in Mexico City. 2015 [6th November 2015]; Available from:http://www.everywomaneverychild. org/images/Global_Maternal_Newborn_Health_Conference/GMNHC_Press_Release_10.17.15.pdf.

3. Temmerman M, Khosla R, Bhutta ZA, Bustreo F. Towards a new Global Strategy for Women's, Children's and Adolescents' Health. BMJ 2015;351:h4414..

4. Global Maternal Newborn Health Conference. The program booklet Mexico City 2015. Available from: https://cdn2.sph.harvard.edu/wp-content/uploads/ sites/44/2015/09/program-final.pdf.

5. Women deliver. Global Maternal and newborn health conference: Social media toolkit. 2015.

6. UNICEF, WHO, World Bank, UN-DESA Population Division;. Levels and trends in child mortality 2015. 2015 [8th November 2015]. Available from: http://childmortality.org/files_v20/download/IGME\%20Report\%202015_9_3\%20LR\%20Web.pdf.

7. Countdown to 2015: Maternal Newborn \& Child Survival. A decade of tracking of progress for maternal,newborn and child survival: The 2015 report 2015. 